\title{
Neoplastic macrovascular invasion represents an independent risk factor for dismal survival in sorafenib treatment for hepatocellular carcinoma
}

\author{
Michele Lecchini', Andrea Olivani', Elisabetta Biasini', Raffaele Dalla Valle², Carlo Ferrari', Gabriele Missale', \\ Claudia Schianchi ${ }^{1}$ \\ ${ }^{1}$ Unit of Infectious Diseases and Hepatology, Azienda Ospedaliero-Universitaria di Parma, Via Gramsci 14, 43126 Parma, Italy. \\ ${ }^{2}$ Department of Surgery, University of Parma, Azienda Ospedaliero-Universitaria di Parma, Via Gramsci 14, 43126 Parma, Italy.
}

Correspondence to: Dr. Gabriele Missale, Unit of Infectious Diseases and Hepatology, Azienda Ospedaliero-Universitaria di Parma, Via Gramsci 14, 43126 Parma, Italy. E-mail: missale@tin.it

How to cite this article: Lecchini M, Olivani A, Biasini E, Dalla Valle R, Ferrari C, Missale G, Schianchi C. Neoplastic macrovascular invasion represents an independent risk factor for dismal survival in sorafenib treatment for hepatocellular carcinoma. Hepatoma Res 2017;3:260-7.

Article history:

Received: 16 Sep 2017

First Decision: 20 Oct 2017

Revised: 1 Nov 2017

Accepted: 2 Nov 2017

Published: 16 Nov 2017

Key words:

Hepatocellular carcinoma,

sorafenib,

neoplastic portal vein thrombosis

\begin{abstract}
Aim: Sorafenib efficacy and safety in advanced hepatocellular carcinoma (HCC) have been demonstrated in two randomized international clinical trials and in clinical practice studies. Because of poor survival advantage, to identify clinical and biological parameters remains an unmet clinical need. Methods: Eighty-four patients treated with sorafenib were evaluated for response to therapy and prognostic factors possibly associated with survival. Results: Median overall survival was 8.5 months. Median duration of therapy was 2.5 months with a median daily dose of $800 \mathrm{mg}$ (IQR 600-800). Dose was adjusted in $52 \%$ of patients. Radiological response to therapy showed a significant impact on survival. Child-Pugh score and neoplastic invasion of the portal system were negatively associated with survival. Continuation of sorafenib even at lower dose was positively correlated with survival. The multivariate analysis identified vascular invasion as the only independent variable: median survival of 5.5 months for neoplastic portal vein thrombosis compared to 12 months in the remaining subjects. Conclusion: A lower sorafenib daily dose is advantageous, even though the reason of this association cannot be explained at present. Neoplastic portal vein thrombosis is strongly associated with dismal survival. Alternative or complementary treatment approaches should be studied in order to improve outcome in this subgroup of patients.
\end{abstract}

\section{INTRODUCTION}

Hepatocellular carcinoma ( $\mathrm{HCC}$ ) is a primary solid tumor of the liver and occurs predominantly in patients with underlying chronic liver disease and cirrhosis. It is the third leading cause of cancer deaths worldwide, with over 570,000 people affected ${ }^{[1,2]}$. The incidence of $\mathrm{HCC}$ is higher in Asia and Africa, where the endemic high prevalence of hepatitis B virus (HBV) and hepatitis $C$ virus (HCV) infections strongly predisposes to the development of chronic liver disease and consequently $\mathrm{HCC}^{[3,4]}$. In developed countries there is the growing

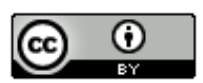

This is an open access article licensed under the terms of Creative Commons Attribution 4.0 International License (https://creativecommons.org/licenses/by/4.0/), which permits unrestricted use, distribution, and reproduction in any medium, as long as the original author is credited and the new creations are licensed under the identical terms.

For reprints contact: service@oaepublish.com

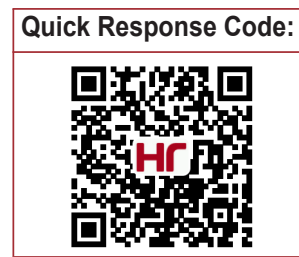


problem of cirrhosis developing in the setting of nonalcoholic fatty liver disease in patients with obesity, type 2 diabetes, dyslipidemia and hypertension ${ }^{[5-8]}$. Programs of surveillance with upper abdomen ultrasound examination and characterization of focal liver lesions with computed tomography (CT) scan or magnetic resonance imaging (MRI) increase the rate of early diagnosis and curative treatments such as surgical resection, liver transplantation and locoregional ablative treatments ${ }^{[9-13]}$ with improved survival. In the advanced stage, Barcelona Clinic Liver Cancer (BCLC) stage C, systemic therapy with sorafenib ${ }^{[14]}$ represents the first line treatment for these patients, while regorafenib is available for second line as well as anti-PD-1 that has been recently approved by the Food and Drug Administration for HCC.

Sorafenib is an oral multi-kinase inhibitor that acts both on tumor cells by inhibiting cytoplasmic cascades RAS-RAF and MEK-ERK, involved in cells proliferation, and also on endothelial cells by blocking plasmatic receptors implicated mainly in neoangiogenesis (VEGFR and PDGFR) ${ }^{[15-19]}$. A correct patient management can increase drug tolerability and seems to improve significantly quality of life and survival ${ }^{[20-24]}$. The opportunity to continue treatment also in patients with radiological progressive disease or when tolerance is poor despite dose adaptation remains controversial ${ }^{[25,26]}$. However, in clinical practice, progression is not always a clear indication to stop sorafenib, especially if there isn't a second-line trial available and in patients with a good Performance Status (PS) with a reasonable life expectancy, an excellent drug tolerance and slow tumor progression. Sorafenib, compared to other target therapies, shows low frequency of radiological responses, but stable disease can be achieved frequently as shown in registration trials ${ }^{[27]}$.

The aim of the present study was to evaluate prognostic relevance of clinical, epidemiological and tumor characteristics on survival. Reported results confirmed that dose reduction is associated with longer survival underlining relevance of drug management to increase tolerability. On the other hand, neoplastic portal vein thrombosis, a condition associated with fast liver decompensation and disease progression, was independently associated with poor clinical outcome.

\section{METHODS}

\section{Patient characteristics}

This is an observational monocentric retrospective study conducted on 84 consecutive subjects starting sorafenib treatment at the Unit of Infectious
Diseases and Hepatology, Azienda OspedalieroUniversitaria di Parma. Data were obtained from the analysis of medical charts and a dedicated database. Inclusion criteria were: radiological or histological diagnosis of HCC not amenable to surgical resection or locoregional treatment, BCLC stage $\mathrm{C}, \mathrm{PS}<2$ according to the Eastern Cooperative Oncology Group system, measurable lesions in CT or MRI scans. Patients with an impaired liver function and a ChildPugh score $\geq 10$ were excluded. Eighty-four patients were considered, 63 males $(75 \%)$ and 21 females $(25 \%)$, with a median age of 73 years (range $32-81$ ) [Table 1]. Of these patients, $45 \%$ had comorbidities: the most frequent was hypertension (29 subjects), followed by diabetes mellitus (16 subjects), previous ischemic vascular events like heart attacks and stroke (11 subjects) and chronic obstructive pulmonary disease (COPD, 9 subjects). Eight subjects had a history of tumors other than HCC [Table 1]. The etiology of chronic liver disease underlying HCC was $\mathrm{HCV}$ infection in 46 patients (54.5\%), nonalcoholic steatohepatitis or alcohol in 21 patients $(25 \%)$, HBV infection in 7 patients (8.5\%), HBV-HCV confection in 3 patients, while in 7 patients $(8.5 \%)$ the cause of liver disease was unknown [Table 1]. Most of subjects (91.5\%) was on a Child-Pugh score A, seven were scored B7 [Table 1]. Majority of patients $(82 \%)$ was previously treated: $72.5 \%$ underwent loco-regional therapies, 33\% surgical resection and $18 \%$ both [Table 1]. Regarding the anatomical characteristics of HCC, it appeared multifocal in $96.5 \%$ of cases and was interested in only one lobe of the liver in $77.5 \%$ of cases, most frequently the right [Table 2]. In 47 patients (56\%) HCC showed signs of neoplastic vascular invasion and 20 subjects $(24 \%)$ presented both vascular invasion and extrahepatic spread [Table 2]. Treatment was stopped at radiological evaluation at 8 weeks of treatment in case of disease progression.

The study was approved by the local ethical committee [Comitato Etico Indipendente (IRB/IEC) of the Azienda Ospedaliero-Universitaria of Parma, Italy].

\section{Treatment with sorafenib and evaluation of response rate}

Sorafenib was administered at a dose of $400 \mathrm{mg}$ bid continuously, equivalent to a total daily dose of $800 \mathrm{mg}$, without food or with a low or moderate fatty meal. Therapy was continuous, but by convention was codified in cycles of 28 days. Patients had to measure their blood pressure at least twice daily and use skin lotions to prevent or reduce any hand-foot syndrome manifestation. Every 4 weeks a revaluation of treatment was planned through a detailed physical examination of patients, the correction of possible adverse effects 
Table 1: Clinical and epidemiological characteristics of patient population at baseline

\begin{tabular}{lc}
\hline Characteristics & Data \\
\hline Gender & \\
Male & $63(74 \%)$ \\
Female & $21(26 \%)$ \\
Age (median years, IQR) & $73(67-75)$ \\
BMI (median, IQR) & $25(23-28)$ \\
Comorbidities (yes/no) & $39(46.5 \%) / 45(53.5 \%)$ \\
Hypertension & $29 / 39$ \\
Diabetes mellitus & $16 / 39$ \\
Cardiovascular events & $11 / 39$ \\
COPD & $9 / 39$ \\
Other tumours & $8 / 39$ \\
Kidney disease & $0 / 39$ \\
Etiology & \\
HCV & $46 / 84(54.5 \%)$ \\
HBV & $3 / 84(3.5 \%)$ \\
HBV + HCV & $7 / 84(8.5 \%)$ \\
Alcohol and/or dysmetabolic & $21 / 84(25 \%)$ \\
Other or unknown & $7 / 84(8.5 \%)$ \\
Child-Pugh score & \\
A5 & $21 / 84(25 \%)$ \\
A6 & $56 / 84(66.5 \%)$ \\
B7 & $7 / 84(8.5 \%)$ \\
Previous treatments (yes/no) & $69(82 \%) / 15(18 \%)$ \\
Resection & $23 / 69$ \\
Loco-regional treatments & $60 / 69$ \\
RFTA & $46 / 60$ \\
TACE & $39 / 60$ \\
PEI & $31 / 60$ \\
Resection + loco-regional treatments & $14 / 69$ \\
\hline & \\
\hline
\end{tabular}

IQR: interquartile range; BMI: body mass index; COPD: chronic obstructive pulmonary disease; HCV: hepatitis C virus; HBV: hepatitis $B$ virus; RFTA: radiofrequency thermal ablation; TACE: transarterial chemoembolization; PEl: percutaneous ethanol injection

(diarrhea, skin rash, high blood pressure, edema), the evaluation of blood tests examinations such as liver function tests (transaminases, albumin, bilirubin), renal function (creatinine, urea, electrolytes), coagulation parameters (prothrombin time), lipase, creatinephosphokinase and the alpha-fetoprotein dosage. It was allowed to reduce sorafenib dose to limit adverse effects of treatment. A thorax-abdomen CT scan with contrast was scheduled at 8 weeks of treatment. The instrumental response to treatment was evaluated according to Modified Response Evaluation Criteria in Solid Tumors criteria ${ }^{[11,12]}$ : complete response (CR) was defined as the disappearance of intra-tumoral arterial enhancement in all target lesions, partial response (PR) as a reduction $>30 \%$ of the sum of the diameters of the vital areas in the parameter lesions and progressive disease (PD) as an increase of $>20 \%$ of the sum of the diameters of the vital areas in the parameter lesions, compared to the baseline size. Stable disease (SD) included all the other cases not classified as PR or PD. In patients classified as not applied, therapy was interrupted before 8 weeks because of liver failure, adverse events or poor performance status.
Table 2: Anatomical and functional characteristics of hepatocellular carcinoma

\begin{tabular}{lc}
\hline Characteristics & Data \\
\hline Location of tumour & \\
$\quad$ Monolobar & $65 / 84(77.5 \%)$ \\
Bilobar & $19 / 84(22.5 \%)$ \\
Extrahepatic spread & \\
Absent & $52 / 84(62 \%)$ \\
Present & $32 / 84(38 \%)$ \\
Macroscopic vascular invasion & \\
Absent & $37 / 84(44 \%)$ \\
Present & $47 / 84(56 \%)$ \\
Metastasis and macroscopic vascular invasion & \\
Both present & $20 / 84(24 \%)$ \\
$\quad$ Both absent & $27 / 84(32 \%)$ \\
Tumour marker at the beginning of therapy & \\
Alpha-fetoprotein (median $\mathrm{ng} / \mathrm{mL})$ & $130.5($ range $1-65,671)$ \\
\hline
\end{tabular}

\section{Sorafenib management and toxicity}

Toxicity was evaluated according to National Cancer Institute Common Terminology Criteria for Adverse Events version $4.0^{[20]}$ every 4 weeks. According to the grade of the event, a dose reduction or suspension of the treatment was planned. For grade 1 adverse events it was advised to institute supportive measures and continue sorafenib treatment; at first appearance of grade 2 adverse events it was suggested to establish support measures and reduce sorafenib at $400 \mathrm{mg} / \mathrm{day}$ for 28 days: if toxicity regressed to grade 1 , it was indicated to re-increase the dose at $400 \mathrm{mg}$ twice daily, otherwise it was recommended to discontinue sorafenib for at least 7 days then $400 \mathrm{mg} / \mathrm{day}$, finally the full dose. At the appearance of the second or third potential grade 2 toxicity, sorafenib was permanently administered at the reduced dose of $400 \mathrm{mg} /$ day. In case of the fourth appearance of grade 2 adverse event it was considered the definitive suspension of treatment. At the occurrence of grade 3 toxicity, sorafenib was interrupted for at least 7 days or until the decrease to grade $0-1$, then prescribed at a low dose (400 mg/day) and further increased to $400 \mathrm{mg}$ twice a day. At the second appearance of grade 3 adverse event, the conduct was the same, but at the time of resumption sorafenib was definitely prescribed a low dose (400 mg/day). In some cases, it was performed a treatment with lower doses than indicated above, up to a minimum of $200 \mathrm{mg} / \mathrm{day}$.

\section{Statistical analysis}

Survival curves are expressed by Kaplan-Meier curves and compared with log-rank test. Cox proportional hazards model was used for multivariate analysis of survival. The variables associated with survival showing a $P$ value $<0.1$ in the univariate analysis were included in the multivariate analysis model, except response rate that was not available for all patients. Prism (Graph Pad) and StatPlus (AnalystSoft Inc.) 
Table 3: Dose, duration and response of treatment

\begin{tabular}{lc}
\hline Characteristics & Data \\
\hline Treatment duration (median months) & 2.5 \\
Response rate & \\
PR & $5 / 84(6 \%)$ \\
SD & $27 / 84(32 \%)$ \\
PD & $26 / 84(31 \%)$ \\
NA & $26 / 84(31 \%)$ \\
Median daily dose mg (IQR) & $800(600-800)$ \\
Patients treated with median dose of $800 \mathrm{mg}$ & $53 / 84(63 \%)$ \\
Patients treated with median dose $<800 \mathrm{mg}$ & $31 / 84(37 \%)$ \\
Dose reduction & \\
Yes & $44 / 84(52 \%)$ \\
No & $40 / 84(48 \%)$ \\
Adverse events (yes/no) & $77(91.5 \%) / 7(8.5 \%)$ \\
Asthenia & $72 / 77(93.5 \%)$ \\
Gastro-intestinal symptoms & $63 / 77(82 \%)$ \\
Rash, peeling, itchy (general) & $48 / 77(62 \%)$ \\
Hypertension & $36 / 77(47 \%)$ \\
HFSR & $27 / 77(35 \%)$ \\
Alopecia & $21 / 77(27 \%)$ \\
Bleeding & $15 / 77(19.5 \%)$ \\
Cardiovascular events & $0 / 77(0 \%)$ \\
Reason of treatment suspension & \\
Progressive disease & \\
Adverse events & $25 / 84(30 \%)$ \\
Liver failure & $23 / 84(27 \%)$ \\
Other reasons & $22 / 84(26 \%)$ \\
\hline
\end{tabular}

PR: partial response; SD: stable disease; PD: progressive disease; NA: not applied; IQR: interquartile range; HFSR: hand-foot skin reaction

were used to perform the statistical analysis. The comparison between mean values was performed with Student $t$ test for unpaired data. Statistical significance was considered for values $P<0.05$.

\section{RESULTS}

\section{Overall picture}

Results on response rate, treatment duration, sorafenib dose and side effects are reported in Table 3: PR was achieved in 5 patients (6\%), SD in $32 \%$ and PD in $31 \%$ of patients. None of patients achieved a CR. Treatment was discontinued for adverse events or clinical worsening before radiological evaluation in 26 patients (31\%). Median treatment duration was 2.5 months. Forty patients $(48 \%)$ received full sorafenib dose ( $800 \mathrm{mg} /$ day) during all the treatment, while 44 subjects $(52 \%)$ reduced sorafenib dose. Median daily dose was $800 \mathrm{mg}$. Thirty-seven percent of patients received a median dose of $800 \mathrm{mg}$, while the remaining (63\%) a minor dose (range 200-600 mg) because of adverse events. Dose reductions ranged between $5 \%$ and $90 \%$ of the time on treatment. Most of patients (92.5\%) developed adverse events: gastro-intestinal symptoms, asthenia, rash and skin peeling and high blood pressure; the most common adverse event was severe weight loss associated with asthenia and diarrhea. Finally, 20 patients after sorafenib discontinuation received other treatments: percutaneous ablative treatments (2 patients) or other systemic treatments such as capecitabine or tivantinib (6 patients).

\section{Survival analysis based on epidemiological and clinical data and previous treatments} Median overall survival was 8.5 months [Figure 1A]. The epidemiological and clinical parameters shown in Table 1 were assessed as factors that could have an effect on survival. Only Child-Pugh score (A vs. B; $P=0.0289$ ) showed an impact on survival, while the remaining epidemiological and clinical characteristics did not show significant differences. History of previous treatment for HCC was a positive factor, however not achieving statistical significance [Table 4], in particular also considering independently locoregional treatments, that represented the most frequent treatment, there was no significant impact on survival (not shown). Eight patients with history of different tumors showed comparable survival to the remaining subjects (not shown).

\section{Impact on survival of HCC characteristics}

Tumor parameters [Table 2] were evaluated as factors potentially influencing survival. Unexpectedly, alphafetoprotein levels, multifocal tumor extended to both lobes as well as extrahepatic spread didn't influence survival significantly. Macroscopic vascular invasion was found to be a strong predictor for survival $(P=$ 0.0141) [Figure 1B], while the association of metastasis and vascular invasion did not worsen patient outcome.

\section{Survival analysis based on response rate, sorafenib dose and treatment duration}

All data related to therapy reported in Table 3 were analyzed as parameters that could influence clinical outcome. As expected, longer duration of therapy (beyond median time of treatment) was positively associated with survival $(P<0.0001)$ [Figure 1C], even though this may not represent an effect of treatment, since other factors like progressive disease or adverse events, could have influenced time on treatment. Response rate showed a significant impact on survival $(P=0.0237)$ [Figure 1D], with median survival of 12.5 months in patients with SD or PR compared to 9.5 months for patients with PD. Dose reduction was a favorable parameter $(P=0.004)$ as well as drug regimen below median daily dose $(P=0.04)$ [Figure $1 \mathrm{E}$ and $\mathrm{F}$ ].

\section{Adverse events and tolerability}

Sorafenib appeared well-tolerated as in previous studies and registration trials, however adverse events were reported, also in this study. Overall incidence of adverse effects was $91.5 \%$ of this cohort [Table 3]. Asthenia, fatigue and gastro-intestinal symptoms 
Table 4: Univariate and multivariate analysis of variables potentially related with survival

\begin{tabular}{|c|c|c|c|c|}
\hline \multirow{2}{*}{ Variables } & \multicolumn{2}{|c|}{ Univariate } & \multicolumn{2}{|c|}{ Multivariate } \\
\hline & $\boldsymbol{P}$ & HR (95\% Cl) & $\boldsymbol{P}$ & HR (95\% Cl) \\
\hline Median age (< 73 vs. $>73$ years) & 0.94 & $0.98(0.60-1.59)$ & & \\
\hline Gender (male vs. female) & 0.96 & $0.98(0.55-1.75)$ & & \\
\hline Comorbidities (yes vs. no) & 0.16 & $0.72(0.44-1.15)$ & & \\
\hline Etiology (only HCV vs. no HCV) & 0.76 & $1.08(0.64-1.82)$ & & \\
\hline Child-Pugh score (A vs. B) & 0.0289 & $0.44(0.09-0.88)$ & 0.093 & $0.48(0.20-1.13)$ \\
\hline $\begin{array}{l}\text { AFP levels }(<130.5 \text { vs. }>130.5 \mathrm{ng}) \\
\text { Response rate (PD vs. PR + SD) }\end{array}$ & $\begin{array}{l}0.28 \\
0.0237\end{array}$ & $\begin{array}{l}0.78(0.47-1.25) \\
2.08(1.10-3.92)\end{array}$ & & \\
\hline Localitation (mono vs. bilobar) & 0.17 & $1.54(0.84-2.66)$ & & \\
\hline Extrahepatic spread (yes vs. no) & 0.42 & $1.20(0.75-2.00)$ & & \\
\hline Macrovascular invasion (yes vs. no) & 0.0141 & $1.73(1.14-3.14)$ & 0.016 & $1.84(1.11-3.05)$ \\
\hline Previous therapies (yes vs. no) & 0.06 & $0.59(0.25-1.04)$ & 0.52 & $0.81(0.42-1.55)$ \\
\hline Dose reduction (yes vs. no) & 0.004 & $0.52(0.29-0.79)$ & 0.45 & $0.73(0.31-1.66)$ \\
\hline Median daily dose (< 800 vs. $800 \mathrm{mg}$ ) & 0.041 & $0.60(0.37-0.98)$ & 0.35 & $0.73(0.37-1.42)$ \\
\hline
\end{tabular}

HCV: hepatitis C virus; AFP: alpha-fetoprotein; PD: progressive disease; PR: partial response; SD: stable disease; HR: hazard ratio; CI: confidence interval

(mainly moderate to serious diarrhea) were the most common adverse events that required patient hospitalization in some cases; rash, itch, hypertension, hand-foot skin reaction (HFSR), alopecia and bleeding were reported in some cases. Cardiovascular events linked to sorafenib treatment were not observed.

\section{Univariate and multivariate analysis of survival according to clinical and anatomical-functional characteristics of cancer at baseline}

All studied parameters were evaluated for their impact on survival. As shown in Table 4 by univariate analysis: Child-Pugh score, neoplastic vascular invasion, dose reduction and median daily dose showed a significant effect. In particular, Child A, absence of vascular invasion, dose reduction and daily dose lower than median were associated with improved survival. Multivariate analysis showed that neoplastic vascular invasion was the only independent condition correlated with a worse outcome $[P=0.0166$; hazard ratio $(\mathrm{HR})=$ $1.846,95 \%$ confidence interval $(\mathrm{Cl})=1.118-3.050]$.

\section{DISCUSSION}

The aim of this study was to analyze the role of epidemiological, clinical, tumor parameters and treatment dose on clinical outcome in a cohort of 84 patients from a single clinical center. Outcome was measured as overall survival. Sorafenib effectiveness was confirmed by response rate, that was significantly associated with survival $(P=0.0237)$. In particular, PR was achieved in 5 patients $(6 \%)$, while SD in 27 patients (32\%).

Metastasis were negatively associated with rate response while there was no significant association with portal thrombosis and intrahepatic tumor burden. Our patients were all in BCLC stage $C$ with majority $(91.5 \%)$ of subjects with compensated liver disease (Child-A) and the remaining patients with Child-B cirrhosis. If compared to previous studies, our patient cohort was characterized by a more advanced tumor stage. In fact, the 2 registration trials included $18 \%{ }^{[28]}$ and $5 \%{ }^{[14]}$ of patients with intermediate $\mathrm{HCC}$ stage (BCLC-B), similarly to real-life studies including 19-25\% of patients that could be classified in the intermediate stage while all our patients were in BCLC-C stage. Even if stage was more advanced, median survival was 8.5 months, comparable to what observed in registration trials ${ }^{[14,28]}$, ranging between 6.5 and 10.7 months and real-life studies ${ }^{[28,29]}$. Median time on treatment was 2.5 months that is indeed less than what reported in other studies ranging between 3.75 and 5.1 months ${ }^{[14,28-30]}$. This may be explained by the more advanced tumor stage of these patients characterized by early disease progression in many cases leading to early discontinuation.

Neoplastic portal thrombosis was present in $56 \%$ of the cases while it ranged between $22 \%$ and $39 \%$ in previous studies ${ }^{[14,28-30]}$. Major causes of early stop of treatment were premature death, hepatic failure, other complications as systemic infections and sorafenib intolerance.

Then we evaluated parameters significantly associated with longer overall survival. Child-Pugh score A, absence of macroscopic vascular invasion and reduced sorafenib daily dose (below median value) were identified by univariate analysis while only absence of neoplastic portal vein thrombosis was independently associated with survival by Cox regression analysis. Multivariate analysis, showed that macroscopic vascular invasion almost doubled the risk of death $(H R=1.846)$, 
A
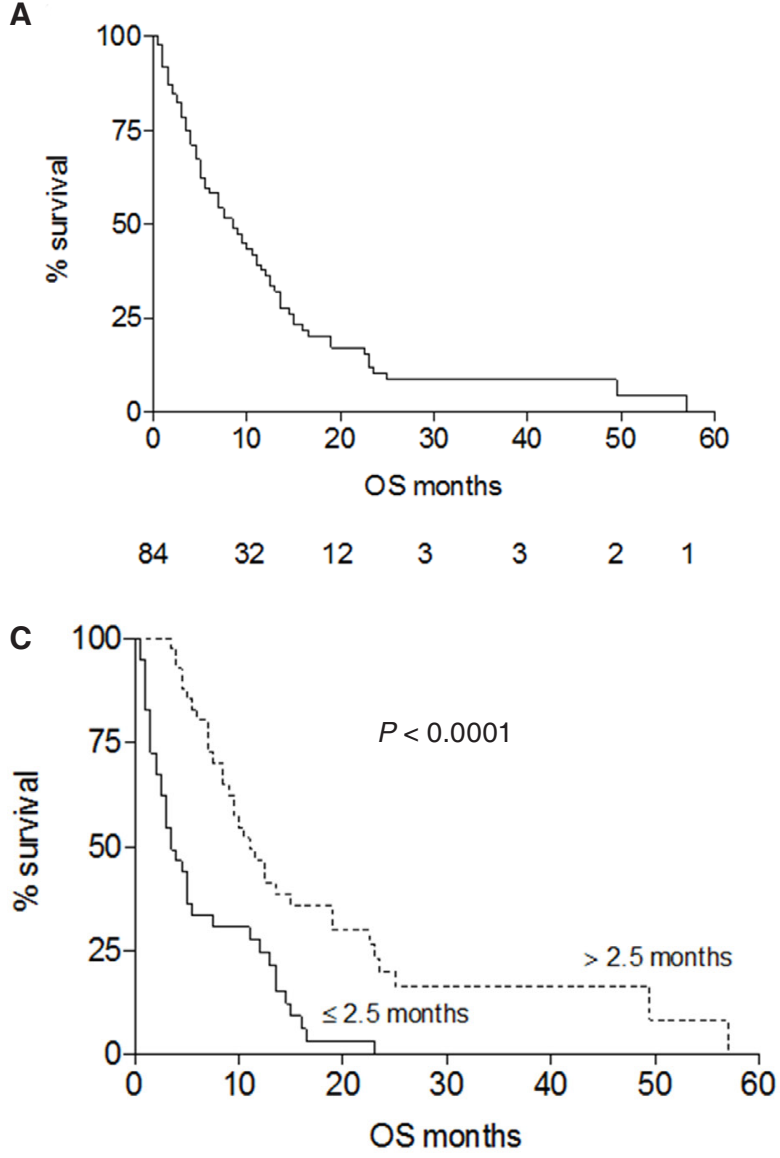

$\begin{array}{lllllll}44 & 24 & 12 & 3 & 3 & 2 & 1 \\ 40 & 11 & 2 & 0 & 0 & 0 & 0\end{array}$

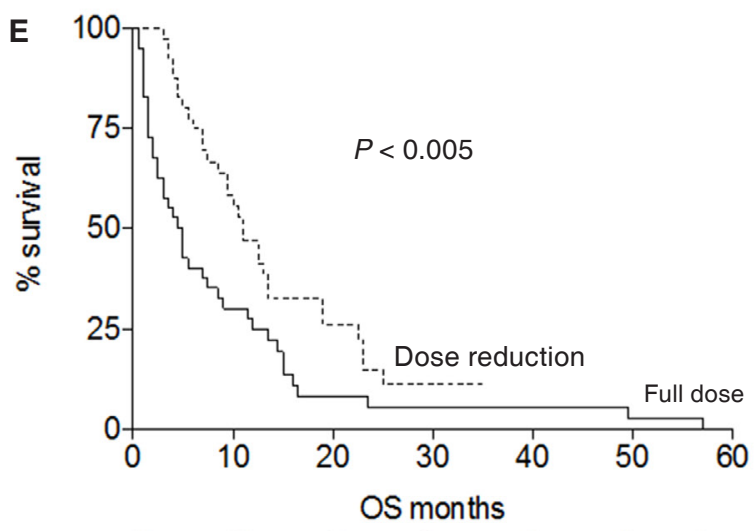

$\begin{array}{lllllll}40 & 12 & 7 & 2 & 0 & 0 & 0 \\ 44 & 21 & 6 & 3 & 3 & 2 & 1\end{array}$

B

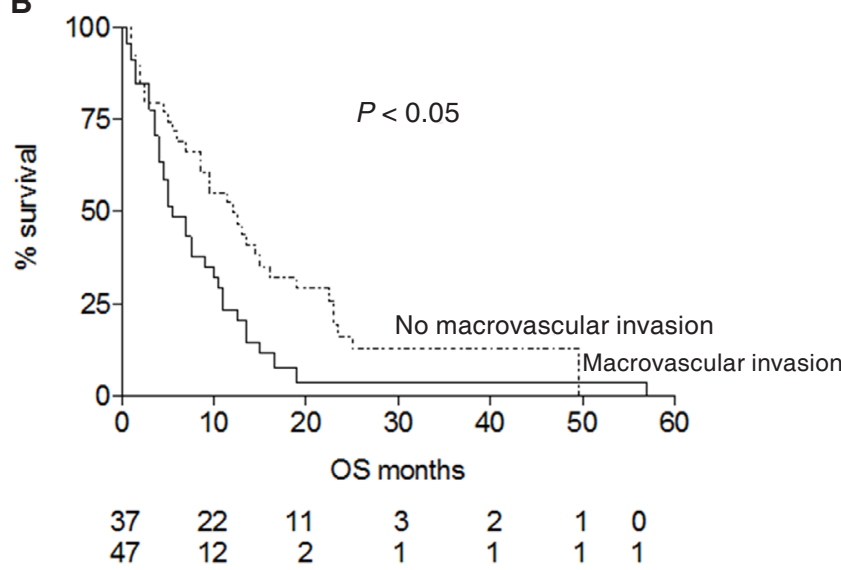

D

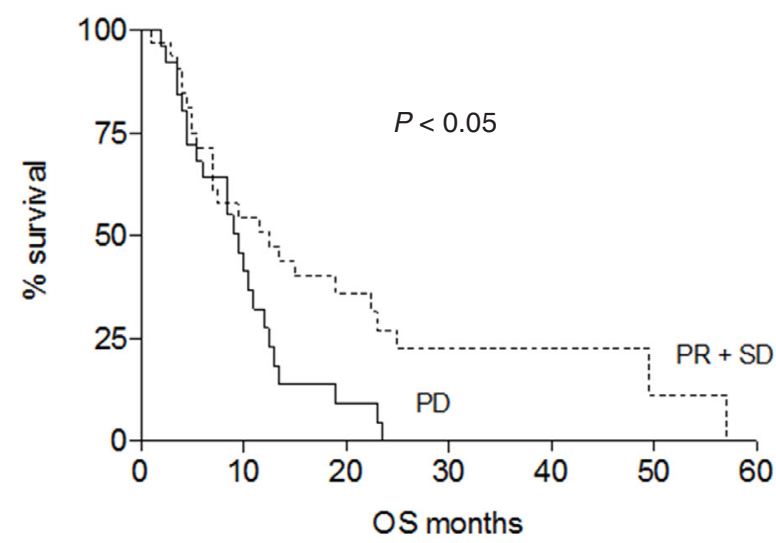

$\mathbf{F}$

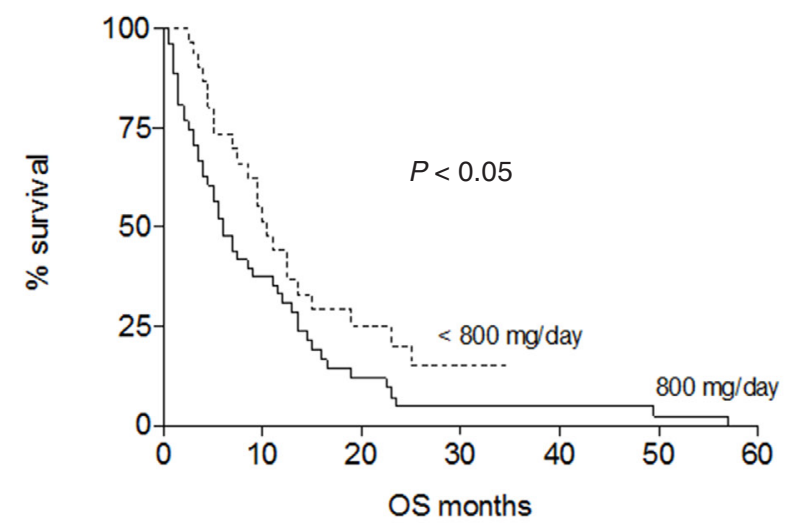

$\begin{array}{lllllll}53 & 18 & 10 & 1 & 0 & 0 & 0 \\ 31 & 15 & 4 & 3 & 3 & 2 & 1\end{array}$

Figure 1: Overall survival (OS) of the whole patient population and survival according to risk factors. (A) Median OS for sorafenib treated patients was 8.5 months; (B) presence of macroscopic neoplastic vascular invasion of the portal venous system, present in $56 \%$ of subjects, was a strong negative predictor on survival, with a median OS of 5.5 vs. 12 months observed in patients without neoplastic thrombosis; (C) a duration of sorafenib treatment beyond median time of 2.5 months positively influenced outcome (median OS 11 vs. 3.5 months); (D) analysis of radiological response rate at 8 weeks of treatment showed a significant impact on survival: median OS was 12.5 month in subjects with stable disease or partial response and 9.5 months in progressive disease patients; (E) dose reduction showed a benefit on survival (median OS 11 vs. 5 months); (F) sorafenib daily dose below median (800 mg) was associated with better survival (median OS 10.5 vs. 6 months)

similarly to what previously reported ${ }^{[28,29]}(\mathrm{HR}=1.7)$, thus confirming that the presence of portal neoplastic thrombosis is a very negative prognostic factor on survival. Indeed, this condition severely impacts on the natural history of the disease, characterized by an aggressive disease course, because of fast spread 
of cancer cells, worsening of portal hypertension and liver function and poorer tolerance to treatment. As evidence of this, majority of patients $(71 \%)$ stopping treatment before radiologic evaluation presented this complication. Neoplastic macrovascular invasion was associated with a survival expectancy less than half, suggesting the usefulness to investigate alternative treatments like combination of different therapies modalities such as external radiotherapy or selective internal radiation therapy ${ }^{[24]}$. Whether best supportive care may represent the best medical option may not be concluded on the base of our findings however it could be considered in selected cases.

Interestingly, sorafenib dose reduction and median daily dose less than $800 \mathrm{mg}$ were positively associated with survival, in fact patients that reduced dose during treatment showed a median survival of 11 months compared to 5 months of the remaining patients. Similarly, it has been reported a survival of 21.6 months compared to 9.6 months for patients treated for more than $70 \%$ of the time at half dose ${ }^{[29]}$. Therefore, a lower dose may be advantageous, enabling a more prolonged treatment, with no reduction of therapeutic effect. In other studies ${ }^{[30,31]}$, starting dose, was analyzed as a variable that could influence management and efficacy of sorafenib showing longer time on treatment and better survival for patients starting with full dose. However, in this study ${ }^{[31]}$ median daily dose was not reported and is not clear if dose reductions allowed longer time on treatment and better outcome.

Treatment adverse events were not significantly different compared to previous reports, registering at least one adverse effects in $91.5 \%$ of our patients. The most common effects didn't differ to what previously reported $^{[14,28-30]}$, represented by asthenia, gastrointestinal symptoms, in particular moderate or severe diarrhea, hypertension and dermatological lesions as systemic rash or HFSR.

In conclusion, portal neoplastic thrombosis is the most important prognostic factor being associated with a rapid clinical deterioration leading to death. Finally, we confirm the importance of clinical management for individualized treatment dose in order to provide longer treatment periods, that seems to be crucial to improve survival of our patients.

\section{DECLARATIONS}

\section{Authors' contributions}

Concept and design: G. Missale, C. Schianchi

Data acquisition: M. Lecchini, E. Biasini

Data analysis: M. Lecchini, A. Olivani, E. Biasini, R.
Dalla Valle, G. Missale

Statistical analysis: A. Olivani, G. Missale

Literature search and manuscript preparation: $M$. Lecchini

Manuscript editing: A. Olivani, C. Ferrari, G. Missale, C. Schianchi

Manuscript review: C. Ferrari, G. Missale, C. Schianchi

\section{Financial support and sponsorship}

This work was supported by FIRB grant from the Italian Ministry of the University and Research, Protocol RBAP10TPXK.

\section{Conflicts of interest}

There are no conflicts of interest.

\section{Patient consent}

Consent was obtained from patients still alive at the time of data collection and analysis.

\section{Ethics approval}

The study was approved by the local ethical committee (Comitato Etico Indipendente (IRB/IEC) of the Azienda Ospedaliero-Universitaria of Parma, Italy).

\section{REFERENCES}

1. Jemal A, Bray F, Center MM, Ferlay J, Ward E, Forman D. Globa cancer statistics. CA Cancer J Clin 2011;61:61-9.

2. Ferlay J, Shin HR, Bray F, Forman D, Mathers C, Parkin DM. Estimates of worldwide burden of cancer in 2008: GLOBOCAN 2008. Int J Cancer 2010;127:2893-917.

3. Schütte K, Bornschein J, Malfertheiner P. Hepatocellular carcinoma-epidemiological trends and risk factors. Dig Dis 2009;27:80-92.

4. Perz JF, Armstrong GL, Farrington LA, Hutin Yj, Bell BP. The contributions of hepatitis $\mathrm{B}$ virus and hepatitis $\mathrm{C}$ virus infections to cirrhosis and primary liver cancer worldwide. J Hepatol 2006;45:52938.

5. Ratziu V, Bellentani S, Cortez-Pinto H, Day C, Marchesini G. A position statement on NAFLD/NASH based on the EASL 2009 special conference. J Hepatol 2010;53:372-84.

6. Loria P, Adinolfi LE, Bellentani S, Bugianesi E, Grieco A, Fargion S, Gasbarrini A, Loguercio C, Lonardo A, Marchesini G, Marra F, Persico M, Prati D, Baroni GS; NAFLD Expert Committee of the Associazione Italiana per lo studio del Fegato. Practice guidelines for the diagnosis and management of non-alcoholic fatty liver disease: a decalogue from the Italian Association for the Study of the Liver (AISF) Expert Committee. Dig Liver Dis 2010;42:272-82.

7. Porepa L, Ray JG, Sanchez-Romeu P, Booth GL. Newly diagnosed diabetes mellitus as a risk factor for serious liver disease. CMAJ 2010;182:E526-31.

8. Polesel J, Zucchetto A, Montella M, Dal Maso L, Crispo A, La Vecchia C, Serraino D, Franceschi S, Talamini R. The impact of obesity and diabetes mellitus on the risk of hepatocellular carcinoma. Ann Oncol 2009;20:353-7.

9. Balogh J, Victor D 3rd, Asham EH, Burroughs SG, Boktour M, Saharia A, Li X, Ghobrial RM, Monsour HP Jr. Hepatocellular carcinoma: a review. J Hepatocell Carcinoma 2016;3:41-53.

10. Colagrande S, Inghilesi AL, Aburas S, Taliani GG, Nardi C, Marra 
F. Challenges of advanced hepatocellular carcinoma. World $J$ Gastroenterol 2016;22:7645-59.

11. Kudo M, Izumi N, Kokudo N, Matsui O, Sakamoto M, Nakashima O, Kojiro M, Makuuchi M. Management of hepatocellular carcinoma in Japan: Consensus-Based Clinical Practice Guidelines proposed by the Japan Society of Hepatology (JSH) 2010 updated version. Dig Dis 2011;29:339-64.

12. Poon D, Anderson BO, Chen LT, Tanaka K, Lau WY, Van Cutsem E, Singh H, Chow WC, Ooi LL, Chow P, Khin MW Koo WH. Management of hepatocellular carcinoma in Asia: consensus statement from the Asian Oncology Summit 2009. Lancet Oncol 2009;10:1111-8

13. Bruix J, Sherman M. Management of hepatocellular carcinoma: an update. Hepatology 2011;53:1020-2.

14. Cheng AL, Kang YK, Chen Z, Tsao CJ, Qin S, Kim JS, Luo R, Feng J, Ye S, Yang TS, Xu J, Sun Y, Liang H, Liu J, Wang J, Tak WY, Pan H, Burock K, Zou J, Voliotis D, Guan Z. Efficacy and safety of sorafenib in patients in the Asia-Pacific region with advanced hepatocellular carcinoma: a phase III randomised, double-blind, placebo-controlled trial. Lancet Oncol 2009;10:25-34.

15. Mendez-Sanchez N, Vasquez-Fernandez F, Zamora-Valdes D, Uribe M. Sorafenib, a systemic therapy for hepatocellular carcinoma. Ann Hepatol 2008;7:46-51.

16. Wilhelm SM, Carter C, Tang L, Wilkie D, McNabola A, Rong H Chen C, Zhang X, Vincent P, McHugh M, Cao Y, Shujath J, Gawlak S, Eveleigh D, Rowley B, Liu L, Adnane L, Lynch M, Auclair D, Taylor I, Gedrich R, Voznesensky A, Riedl B, Post LE, Bollag G, Trail PA. Sorafenib (BAY 43-9006, Nexavar) exhibits broad spectrum oral antitumor activity and targets the RAF/MEK/ERK pathway and receptor tyrosine kinases involved in tumor progression and angiogenesis. Cancer Res 2004;64:7099-109.

17. Adnane L, Trail PA, Taylor I, Wilhelm SM. Sorafenib (BAY 439006, Nexavar), a dual-action inhibitor that targets RAF/MEK/ERK pathway in tumor cells and tyrosine kinases VEGFR/PDGFR tumor vasculature. Methods Enzymol 2006;407:597-612.

18. Liu L, Cao Y, Chen C, Zhang X, Mc Nabola A, Wilkie D, Wilhelm $\mathrm{S}$, Lynch M, Carter C. Sorafenib blocks the RAF/MEK/ERK pathway, inhibits tumor angiogenesis, and induces tumor cell apoptosis in hepatocellular carcinoma model PLC/PRF/5. Cancer Res 2006;66:11851-8.

19. Wilhelm SM, Adnane L, Newell P, Villanueva A, Llovet JM, Lynch M. Preclinical overview of sorafenib, a multikinase inhibitor that targets both Raf and VEGF and PDGF receptor tyrosine kinase signaling. Mol Cancer Ther 2008;7:3129-40.

20. Di Marco V, De Vita F, Koskinas J, Semela D, Toniutto P, Verslype C. Sorafenib: from literature to clinical practice. Ann Oncol 2013;24:ii30-7.

21. Choi GH, Han S, Shim JH, Ryu MH, Ryoo BY, Kang YK, Kim KM, Lim YS, Lee HC. Prognostic Scoring Models for patients undergoing sorafenib treatment for advanced stage hepatocellular carcinoma in real-life practice. Am J Clin Oncol 2017;40:167-74.

22. Kudo M, Ueshima K, Arizumi T. Real life clinical practice with sorafenib in advanced hepatocellular carcinoma: a single-centre experience. Dig Dis 2012;30:609-16.

23. Trojniak MP, Palozzo AC, Mazurek M, Jirillo A. Sorafenib in hepatocellular carcinoma - a post marketing evaluation. Immunopharmacol Immunotoxicol 2012;34:419-22.

24. Chan SL, Chong CC, Chan AW, Poon DM, Chok KS. Management of hepatocellular carcinoma with portal vein tumor thrombosis: review and update at 2016. World J Gastroenterol 2016;22:7289-300.

25. Miyahara K, Nouso K, Morimoto Y, Takeuchi Y, Hagihara H, Kuwaki K, Onishi H, Ikeda F, Miyake Y, Nakamura S, Shiraha H, Takaki A, Iwadou S, Kobayashi Y, Takaguchi K, Takuma Y, Takabatake H, Sakaguchi K, Yamamoto K; Okayama Liver Cancer Group. Efficacy of sorafenib beyond first progression in patients with metastatic hepatocellular carcinoma. Hepatol Res 2014;44:296-301

26. Nakano M, Tanaka M, Kuromatsu R, Nagamatsu H, Tajiri N, Satan M, Niizeki T, Aino H, Okamura S, Iwamoto H, Shimose S, Shirono T, Koga H, Torimura T; Kurume Liver Cancer Study Group of Japan. Sorafenib for the treatment of advanced hepatocellular carcinoma with extrahepatic metastasis: a prospective multicenter cohort study. Cancer Med 2015;4:1836-43.

27. Raoul JL, Adhoute X, Gilabert M, Edeline J. How to assess the efficacy or failure of targeted therapy: deciding when to stop sorafenib in hepatocellular carcinoma. World J Hepatol 2016;8:1541-6.

28. Llovet JM, Ricci S, Mazzaferro V, Hilgard P, Gane E, Blanc JF, de Oliveira AC, Santoro A, Raoul JL, Forner A, Schwartz M, Porta C, Zeuzem S, Bolondi L, Greten TF, Galle PR, Seitz JF, Borbath I, Häussinger D, Giannaris T, Shan M, Moscovici M, Voliotis D, Bruix J; SHARP Investigators Study Group. Sorafenib in advanced hepatocellular carcinoma. N Engl J Med 2008;359:378-90.

29. Iavarone $\mathrm{M}$, Cabibbo G, Piscaglia F, Zavaglia C, Grieco A, Villa E, Cammà C, Colombo M; SOFIA (SOraFenib Italian Assessment) study group. Field-practice study of sorafenib therapy for hepatocellular carcinoma: a prospective multicenter study in Italy. Hepatology 2011;54:2055-63.

30. D'Angelo S, Germano D, Zolfino T, Sansonno D, Giannitrapan L, Benedetti A, Montesarchio V, Attili A, Buonadonna A, Barni S, Gasbarrini A, Burlone ME, Cillo U, Marenco S, Villa E, Giovanis P, Proserpio I, Saitta C, Magini G, Cengarle R, Fava G, Cuttone F, Calvani N, Angelico M, Di Costanzo F, Noto A, Poggi G, Marignani M, Cascinu S, Amoroso D, Palmieri V, Massa E, Crocè LS, Picardi A, Tumulo S, Erminero C, Lencioni R, Lorusso V. Therapeutic decisions and treatment with Sorafenib in hepatocellular carcinoma: final analysis of GIDEON study in Italy. Recent Prog Med 2015;106:217-26.

31. Kim DY, Kim HJ, Han KH, Han SY, Heo J, Woo HY, Um SH, Kim YH, Kweon YO, Lim HY, Yoon JH, Lee WS, Lee BS, Lee HC, Ryoo BY, Yoon SK. Real-life experience of sorafenib treatment for hepatocellular carcinoma in Korea: from GIDEON data. Cancer Res Treat 2016;48:1243-52. 